\title{
Research-Based Learning Applied in First Semester Courses of Engineering Programs (preliminary study)
}

\author{
C. J. Diliegros-Godines ${ }^{1}$, Adriana Erika Martínez-Canton², Victoria Ubici ${ }^{3}$ \\ 1,2Tecnologico de Monterrey, Av. Atlixcayotl 5718, Reserva Territorial Atlixcáyotl, 72453 Puebla, Pue. \\ ${ }^{3}$ Tecnologico de Monterrey, Av. Eugenio Garza Sada 2501 Sur, Tecnológico, 64849 Monterrey, N.L. \\ 1jdiliegros@tec.mx
}

\begin{abstract}
The development of research abilities is a necessary competency for students of Engineering and Science. Regardless of the engineering field of interest, the development of global competencies influences their professional performance. In the present work, we describe the impact, from the students' perception, of the early approach in research activities that involves critical thinking, innovation, problem-solving, self-direction, leading, and written communication abilities. To introduce the students to Research-Based Learning (RBL), we asked them to develop a solution to a problem presented in a first-semester science class in a university focused on developing technical and transversal competencies. This work proposes a teaching methodology based on RBL, which includes the appropriate use of search tools, data analysis, and writing skills, taking advantage of the institution's resources. Simultaneously, we looked for an effective research methodology to build a solid theoretical framework relevant to their experimental results. Moreover, we aimed to link the theoretical course contents to the student's engineering field through RBL activities. The sample under study had 98 students taking an experimental physics and statistical analysis course; 49 in an experimental group (class) were guided using RBL, and the other students were in the control group. The evaluation of the learning outcomes was carried out comparing the pre-and-post surveys, using a 5-point Likert scale (ranging from strongly disagree to strongly agree). The statistical analysis of the experimental guided group results showed an increase in critical thinking, innovation, problem-solving, and self-direction compared to the control group students. However, the leadership competency did not show any improvement in both groups. We concluded that implementing the RBL methodology for students in the early stages of engineering education promoted and reinforced the development of technical and transversal competencies
\end{abstract}

Keywords

Educational Innovation, Research-based Learning, Learning Activities, Higher Education Transversal Competencies

Article Received: 10 August 2020, Revised: 25 October 2020, Accepted: 18 November 2020

\section{Introduction}

Research-based learning (RBL) has become a primary educational methodology to develop professional competencies in higher education. Studies have reported several advantages of using RBL in all areas of undergraduate education, such as engineering [1,2], medicine [3], physiology [4], and teacher education [5], among others. In particular, Singh et al. [6] have shown that the use of RBL by engineering undergraduates develops and enhances problem-solving, domain knowledge, language and communication, information and communication technology (ICTs), general learning, academic knowledge, attitude, and ethical skills. Through RBL strategy, MayoloDeloisa et al. [7] demonstrated that students taking theoretical and laboratory courses in Enzymology and Biocatalysis could generate experimental data and develop competencies to acquire knowledge, attain outstanding commitment, and improve research skills. The RBL technique is usually implemented during the last year of undergraduate study or postgraduate [8]; however, an earlier introduction to RBL can significantly impact the development of skills for the students' chosen occupational fields.

The teaching and learning processes necessary to implement RBL still challenges professors. There are four principal barriers: 1) teacher mindset, 2) teaching methodology, 3) curricular design, and 4) academic leadership [9]. It has been observed that, depending on the professor's experience and the course focus, the inclusion of RBL in higher education leads to several strategies. Consequently, the student experience of RBL can be broad and shallow and may not be sufficient for them to achieve the academic or competency level desired [5].

In this work, we propose a simple teaching methodology based on research activities applied in a second-semester higher education course called "Experimental Physics and Statistical Thinking" in the School of Engineering and Sciences (SES) at Tecnologico de Monterrey. Here, the evaluation of the students' perception of developing their skills and competencies was carried out comparing pre-andpost-surveys, using a 5-point Likert scale [10] (strongly disagree to strongly agree). The results showed that the students perceived that the activities helped them increase their technical and transversal competencies.

\section{Methodology}

This work is based on the early-stage immersion of students into a well-structured RBL methodology. The sample under study was composed of 98 students of an experimental physics and statistical analysis course, where only 49 students were guided using the RBL, and the rest were part of the control group. It is important to mention that the course was carried out in a five-week period in the middle of the semester, and the students came from all the engineering specialties.

The first step was to introduce the students to the digital 
library and database available in the university. The students received a 1-hour workshop about digital resources and how to use them.

\subsection{Evaluation of student's perception of technical and transversal competencies}

In order to perform statistical analysis, the authors applied two online surveys asking students to rate statements about their learning on a Likert scale [10] with five options: 1) Strongly disagree, 2) Disagree, 3) Somewhat agree, 4) Agree, 5) Strongly agree. All the statements were phrased in such a manner that the higher scores indicated a positive result.

\subsubsection{Pre-survey}

The pre-survey was applied at the beginning of the course and included the following questions:

Q1. Rate your skill level in the following transversal competencies:

\begin{tabular}{ll}
- & Critical thinking (CT) \\
- & Innovation (In) \\
- & Leadership (Le) \\
- & Problem-solving (PS) \\
\hline & Self-direction (SD)
\end{tabular}

Q2. Rate your skill level in the following technical competencies:

- Scientific Methodology in engineering problems

(SM)

- $\quad$ Correct use of mathematical tools (MT)

- $\quad$ Observation ability (OA)

- Use of graphs to perform statistical analysis (SA)

- Understanding of nanotechnology concepts (NT)

- $\quad$ Ability to identify relevant information to conduct research $(\mathrm{RI})$

Q3. What are the sources of information that you usually use?

Q4. Rate the frequency of use of the following digital resources: Google, Google Scholar, ScienceDirect, and the Digital Library from this institution.

\subsubsection{Post-survey}

The post-survey (exit survey) was applied at the end of the course. It asked the students to reflect on how their technical and transversal competencies improved due to taking the course. This was evaluated using similar questions to Q1 and Q2 in the pre-survey.

Also, the following questions were included:

Q3. How much did your interest in research increase after the course?

Q4. How much did your ability to search and choose information relevant to your activity increase?

The scale reliability of the pre-and-post tests was measured for internal consistency through Cronbach's alpha. Values of this statistic above 0.70 were considered to represent adequate reliability and right internal consistency $[4,11]$. The values of the tests' samples showed good reliability with alfa between 0.74 and 0.83 .

\subsection{Activities proposed}

As mentioned, this work proposed a simple methodology to implement RBL in higher education. The activities proposed are shown in Table 1. It is essential to mention that all the activities must be guided by the professor and include continuous feedback to the students.

\subsection{Statistical analysis}

The students' answers about their perception of the development of competencies were analyzed by comparing the final answer in their level of skill perception with the initial answer using Excel and Minitab. A percentage difference in both answers was calculated: $\Delta \%=$ the postsurvey answer minus the pre-survey answer for each competency. Negative values obtained in the lower Likert scale (1 and 2) and positive values on the high end of the scale (4 and 5) meant that the student's perception was they improved their competency. On the other hand, a positive value on the lower end (1 and 2) and a negative value on the high end (4 and 5) indicated student confusion about their competency.

Also, to prove the efficiency of research-based learning, the pre-and-post survey results were compared and analyzed using the Shapiro Wilk normality test. All the tests showed $p$ $>0.05$, implying that the samples were normally distributed [12]. Then, paired-sample t-tests were conducted comparing the students' perceived learning outcomes to identify significant statistical differences $[13,14]$.

Table 1. Description of activities using RBL methodology.

\begin{tabular}{|c|c|c|}
\hline Learning Activity & Objective & Time of the course \\
\hline $\begin{array}{l}\text { Key questions about } \\
\text { the activity guided } \\
\text { bibliographical } \\
\text { research about the } \\
\text { problem to solve. }\end{array}$ & $\begin{array}{l}\text { To help the student } \\
\text { recognize } \\
\text { trustworthy digital } \\
\text { resources available } \\
\text { in their institution to } \\
\text { perform scientific } \\
\text { research. }\end{array}$ & First week. \\
\hline 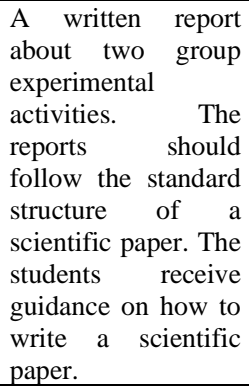 & $\begin{array}{l}\text { To evaluate student } \\
\text { competencies and } \\
\text { abilities related to } \\
\text { RBL. } \\
\text { To provide feedback } \\
\text { to the students after } \\
\text { each delivered } \\
\text { report to improve } \\
\text { their competencies } \\
\text { for the next reports. }\end{array}$ & $\begin{array}{l}\text { Second and third } \\
\text { weeks. }\end{array}$ \\
\hline $\begin{array}{l}\text { Advanced } \\
\text { bibliographical } \\
\text { research about the } \\
\text { problem to solve. } \\
\text { This research } \\
\text { focused on } \\
\text { published papers } \\
\text { and patents. }\end{array}$ & $\begin{array}{l}\text { To narrow the } \\
\text { information search } \\
\text { to relevant } \\
\text { published works. To } \\
\text { provide final } \\
\text { feedback to the } \\
\text { students. }\end{array}$ & Fourth week. \\
\hline $\begin{array}{l}\text { Written and oral } \\
\text { presentations about } \\
\text { the solution } \\
\text { proposed for the } \\
\text { established problem. }\end{array}$ & $\begin{array}{l}\text { To evaluate the } \\
\text { competencies of the } \\
\text { students. }\end{array}$ & Fifth week. \\
\hline
\end{tabular}




\section{Results}

The pre-survey questions Q3 and Q4 showed that the most used digital resource was Google (Likert rating 5), followed by Google Scholar (rating 4), Digital Library (rating 4), and ScienceDirect (rating 1).

The $\Delta \%$ results for the pre-and-post surveys are shown in Figure 1 for transversal competencies and Figure 2 for technical competencies. In general, there is an increase in the transversal and specific competencies for all the students. However, we can observe differences between the RBL and control groups.

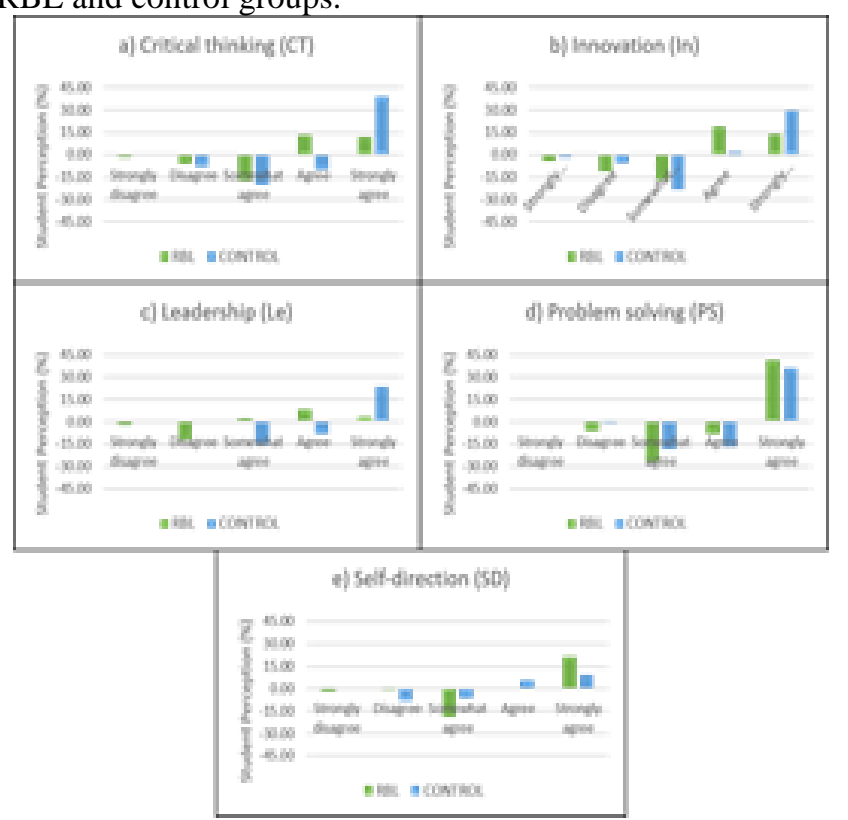

Figure 1. Student perception of skill levels in transversal competencies.

The control group had more freedom to perform their activities; this was reflected in an increase in their perception of the CT, In, and Le competencies (Figure 1, a to c). On the other hand, the RBL group showed a remarkable improvement in PS and SD competencies (Figure 1, d to e).

In Figure 2 for technical competencies, we can observe that the RBL group perception of SM and MT competencies was deficient at the beginning of the course. However, after using the RBL methodology, the students reported a significant improvement in their skill levels, moving from Likert scale 1-2 to 5 on the scale. On the other hand, the control group showed an increment of only one level on the scale from pre-survey to post-survey in the SM and MT competencies. In the OA and SA competencies (Figure 2, c and $\mathrm{d}$ ), both groups had dispersed perception in the presurvey and improvement to levels 4 and 5 after the course, which was intended by the course design and objectives.

The competencies strongly associated with research, such as NT and RI, are the ones that showed the most significant improvement due to the RBL methodology. In Figure 2 e and $f$, it can be observed that the RBL group perceived an increase in those skill competencies, rating them 4 to 5 on the Likert scale after the course, while the control group had a dispersed perception of their skills.

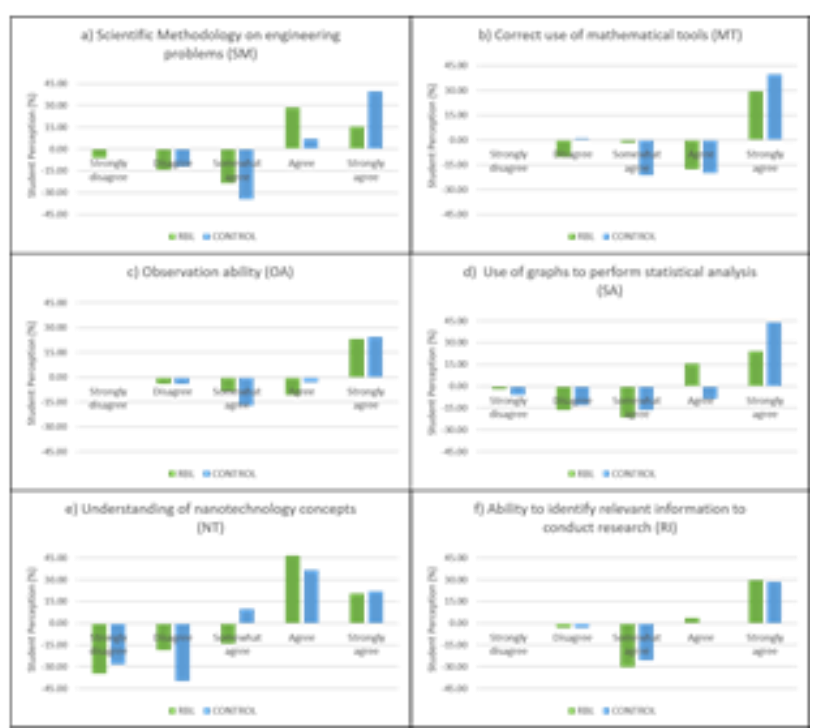

Figure 2. Student perception of skill levels in technical competencies.

The highest impact of the RBL methodology was measured in the Q4 post-survey question. Figure 3 shows that more than $50 \%$ of the RBL group students believed their research skills for relevant information had highly improved. In contrast, the control group's opinion about that technical skill was dispersed.

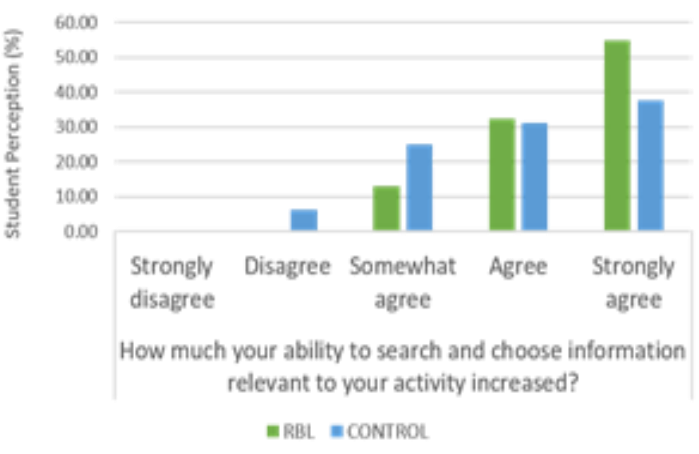

Figure 3. Students' perception of their search skills and choosing relevant information.

To support the observations made by the $\Delta \%$ study, we performed paired-sample t-tests for transversal and technical competencies on the whole sample of students (i.e., 98 students). The results are shown in Tables 2 and 3.

According to the p-values calculated with Minitab, a significance level $(\alpha)$ of 0.05 indicates that for the CT, In, PS, and SD competencies, the null hypothesis was rejected, meaning that the differences between the initial value and the final values of each competency are less than zero. In other words, a significant difference between the initial value and the final value of the competencies was observed, implying that the RBL helps improve those skills in the students.

For the Leadership competency, the null hypothesis was accepted, concluding that there is insufficient information to say that the RBL improves this skill. 
Table 2. Paired T-test for transversal competencies.

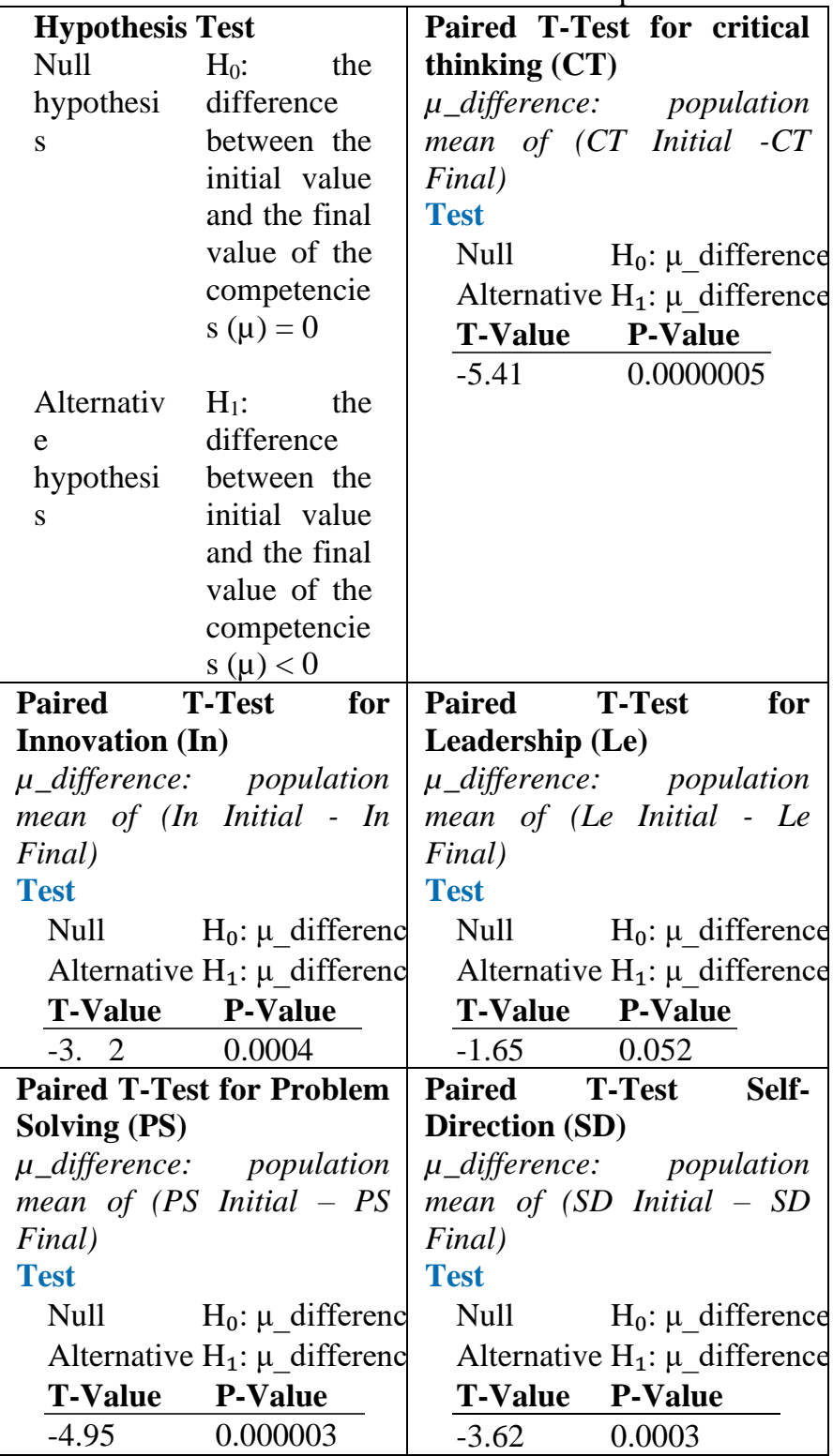

Regarding the results obtained in Minitab for the technical competencies, there is a significant difference between the pre-and-post survey values, meaning that the RBL improves the SM, MT, OA, SA, NT, and RI competencies (See Table 2).

Table 2. Paired T-test for specific competencies.

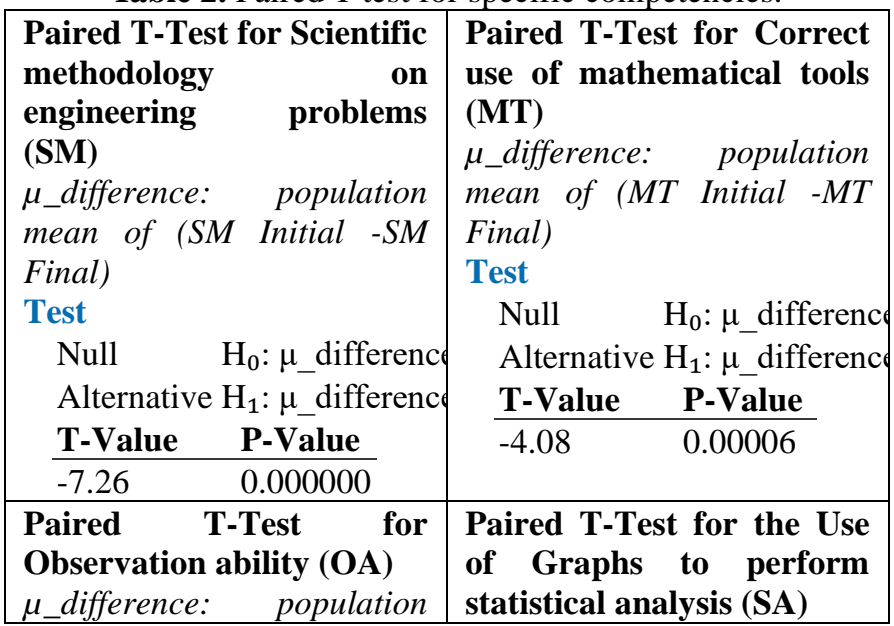

\begin{tabular}{|c|c|}
\hline $\begin{array}{l}\text { mean of (OA Initial - } O A \\
\text { Final) }\end{array}$ & $\begin{array}{lr}\text { M_difference: } & \text { population } \\
\text { mean of (SA Initial - SA }\end{array}$ \\
\hline Test & Final) \\
\hline $\mathrm{H}_{0}: \mu \_$difference & Test \\
\hline Alternative $\mathrm{H}_{1}: \mu \_$difference & $\mathrm{H}_{0}: \mu \_$differ \\
\hline P-Value & Alternative $\mathrm{H}_{1}: \mu$ diff \\
\hline 0.00124 & T-Value \\
\hline & 0.00000 \\
\hline T-Test & Paired T-Test fo \\
\hline $\begin{array}{l}\text { Understanding } \\
\text { nanotechnology concepts } \\
\text { (NT) }\end{array}$ & $\begin{array}{ll}\text { to identify } & \text { relevant } \\
\text { information to } & \text { conduct } \\
\text { research }(\mathrm{RI}) & \end{array}$ \\
\hline $\begin{array}{l}\mu_{\text {_difference: }} \text { population } \\
\text { mean of (NT Initial }-N T \\
\text { Final) }\end{array}$ & $\begin{array}{l}\mu_{\text {_difference: }} \text { population } \\
\text { mean of }(R I \text { Initial }-R I \\
\text { Final) }\end{array}$ \\
\hline Test & Test \\
\hline $\mathrm{H}_{0}: \mu \_$difference & $\mathrm{H}_{0}: \mu \_$differ \\
\hline Alternative $\mathrm{H}_{1}:$ & Alternative $\mathrm{H}_{1}: \mu \_$differ \\
\hline T-Value & T-Value \\
\hline 0.0000 & -5.63 \\
\hline
\end{tabular}

These results are similar to those observed in Figures 1 and 2. However, a more in-depth study must be made to clearly identify the RBL method's contribution in the early years' education of engineering students.

As can be observed, the use of RBL in theoretical and practical courses positively impacts the competencies, improving them. This was also observed in the study performed by Mayolo-Deloisa et al. [7], where through RBL strategy, students in an Enzymology and Biocatalysis course were able to generate experimental data and develop competencies for knowledge acquisition, gain a higher commitment level, and improve their research skills. Similar observations were reported by Noguez et al. [15] for undergraduate Computational Engineering students. Several approaches have been made to improve the development of technical and transversal competencies; however, not all of them showed successful results compared with traditional teaching [13].

\section{Conclusions}

The data collected in the present study shows that the students knew about the searching tools and how to use them. However, their skills to recognize trustworthy digital sources to perform relevant scientific research were poor before taking the course employing the RBL methodology. The students' perception of their technical skills shows significant improvement. Of the transversal competencies, the students expressed feeling a higher mastery of PS and DS after the RBL. The technical competencies NT and RI show the best improvement as a result of using the RBL methodology. This proposed methodology can be extended to other types of courses. Encouraged by these results, we intend to employ the methodology in other undergraduate engineering courses and other fields, such as business and medicine, in the early stages of the students' education. 


\section{Acknowledgments}

The authors acknowledge the financial and technical support of Writing Lab, Institute for the Future of Education, Tecnologico de Monterrey, Mexico, in the production of this work. We also acknowledge the Science Department and the Teaching Assistant Program of Tecnologico de Monterrey, Campus Puebla.

\section{References}

[1] A. Suwito, Purwanto, N.I. Parta, S. Irawati, J.W. Dika, Reducing the main problem of proposals in undergraduate research through research-based learning activity students, TEM J. 8 (2019) 12131217. doi:10.18421/TEM84-15.

[2] E. Ruiz-Ramos, J.M. Romero-García, F. Espínola, I. Romero, V. Hernández, E. Castro, Learning and researching based on local experience and simulation software for graduate and undergraduate courses in chemical and environmental engineering, Educ. Chem. Eng. 21 (2017) 50-61. doi:10.1016/j.ece.2017.05.001.

[3] C. Sota, K. Peltzer, The Effectiveness of Research Based Learning among Master degree Student for Health Promotion and Preventable Disease, Faculty of Public Health, Khon Kaen University, Thailand, Procedia - Soc. Behav. Sci. 237 (2017) 1359-1365.

doi:10.1016/j.sbspro.2017.02.226.

[4] F.A. Santirso, M. Martin-Fernández, M. Marco, V. Vargas, M. Lila, E. Gracia, La investigación visita el aula: la promoción del conocimiento y la práctica de la investigación como estrategia docente innovadora, doi:10.4995/inred2017.2017.6801.

[5] A. Brew, C. Saunders, Making sense of research-based learning in teacher education, Teach. Teach. Educ. 87 (2020) 102935. doi:10.1016/j.tate.2019.102935.

[6] R. Singh, Devika, C. Herrmann, S. Thiede, K.S. Sangwan, Research-based Learning for Skills Development of Engineering Graduates: An empirical study, Procedia Manuf. $31 \quad$ (2019) 323-329. doi:10.1016/j.promfg.2019.03.051.
[7] K. Mayolo-Deloisa, A.M. Ramos-de-laPeña, O. Aguilar, Research-based learning as a strategy for the integration of theory and practice and the development of disciplinary competencies in engineering, Int. J. Interact. Des. Manuf. 13 (2019) 1331-1340. doi:10.1007/s12008-01900585-4.

[8] Suntusia, Dafik, Hobri, The effectiveness of Research Based Learning in improving students' achievement in solving twodimensional arithmetic sequence problems, Int. J. Instr. 12 (2019) 17-32. doi:10.29333/iji.2019.1212a.

[9] W. Rattanaprom, Failure of ResearchBased Learning Implementation in Basic Education, Int. Educ. Stud. 12 (2019) 19. doi:10.5539/ies.v12n4p19.

[10] R. Likert, A technique for the measurement of attitudes, Arch. Psychol. 22 (1932) 55.

[11] S.F.E. Rovers, G. Clarebout, H.H.C.M. Savelberg, J.J.G. van Merriënboer, Improving student expectations of learning in a problem-based environment, Comput. Human Behav. 87 (2018) 416-423. doi:10.1016/j.chb.2018.02.016.

[12] A. Wedel, C.R. Müller, J. Pfetsch, A. Ittel, Training teachers' diagnostic competence with problem-based learning: A pilot and replication study, Teach. Teach. Educ. 86 (2019) 102909. doi:10.1016/j.tate.2019.102909.

[13] P. Garnjost, S.M. Brown, Undergraduate business students' perceptions of learning outcomes in problem based and faculty centered courses, Int. J. Manag. Educ. 16 (2018) 121-130. doi:10.1016/j.ijme.2017.12.004.

[14] J.L. Devore, Probability and statistics for Engineering and the Sciences, in: 9th ed., CENGAGE, 2016: pp. 382-388.

[15] J. Noguez, L. Neri, Research-based learning: a case study for engineering students, Int. J. Interact. Des. Manuf. 13 (2019) 1283-1295. doi:10.1007/s12008019-00570-х 